\title{
Intensive care in tetanus: management, complications, and mortality in 100 cases
}

\author{
R S EDMONDSON, M W FLOWERS
}

British Medical fournal, 1979, 1, 1401-1404

\section{Summary and conclusions}

One hundred cases of tetanus were treated in the intensive care unit of Leeds General Infirmary during 1961-77. In 90 patients disease was severe enough to require paralysis and artificial ventilation; a further three needed tracheostomy but not paralysis; and in seven the condition was mild, requiring sedation only. Ten patients died, but all deaths were attributable to complications of treatment rather than to the disease itself and were theoretically avoidable. No evidence of permanent neurological damage from tetanus was found. In 65 patients a wound was the source of infection, most of which were minor, often receiving no medical attention. In five patients the source was probably varicose ulcers of the leg. Such patients, if lacking immunity, are at risk, particularly when farming or gardening. Only two patients had received a full course of tetanus toxoid, in one case eight years and in the other three years before injury; neither received a booster dose at the time of injury and in the second tetanus was mild. Of the 35 patients who did seek medical attention at the time of wounding, 21 received prophylactic antibiotics and 25 tetanus toxoid, but none received equine or human antitetanus serum.

Early resort to tracheostomy and paralysis in severe

Leeds General Infirmary, Leeds LS1 3EX

R S EDMONDSON, MB, FFARCS, consultant anaesthetist

$M$ W FLOWERS, MB, FRCS, consultant, accident and emergency department tetanus resulted in a favourable mortality of $10 \%$ in the series. To implement such a policy full intensivecare facilities, with a trained nurse to care for each patient, must be available at all times.

\section{Introduction}

Tetanus is now rare in Britain, only 16 cases being notified in 1977 for England and Wales. Nevertheless, the intensive care unit at Leeds General Infirmary, which is the regional referral unit for tetanus, continues to receive a few cases each year. Despite full facilities mortality is still appreciable $(10 \%$ in this series) and since the average stay of these patients in the unit is 31 days, treatment is expensive in terms of staff and resources.

\section{Patients}

Seventy-five patients were men and 25 women; this preponderance of men probably reflects their greater exposure to tetanus-prone injury and is found in other series. ${ }^{1}$ Ages ranged from 5 to 87, with the highest incidences in childhood and the elderly.

\section{PRESENTATION}

Most patients presented with classical tetanus, with a remarkable uniformity of clinical features. Trismus and dysphagia, often described by the patient as "sore throat," were the first symptoms in 75 . Pain and stiffness in the neck and back were the first complaint in 14, but all except one had trismus on examination or quickly developed it. The exception was a boy who had recently arrived from Bangladesh. His symptoms were quite atypical throughout the illness, and he developed spasms but little or no trismus.

Six of the nine patients with wounds around the head and neck presented with "cephalic tetanus" with cranial nerve palsies, which 
sometimes caused considerable difficulty in diagnosis. All six had a predominantly unilateral facial palsy and two also showed weakness of the extraocular muscles, which caused diplopia. All developed trismus and generalised tetanus. Three patients presented with "local tetanus," two with stiffness of the hand and forearm after hand wounds and one with "stiff toes" after a calf wound. All had trismus and developed severe, generalised tetanus. Abdominal pain was the first symptom in the remaining two patients, which, together with abdominal rigidity, is a source of difficulty in diagnosis: both developed generalised tetanus shortly afterwards.

Some patients were referred with suspected tetanus but were subsequently found to have various other conditions. The commoner causes of confusion were hysteria, dystonic reactions to drugs such as perphenazine (Fentazin) and metoclopramide (Maxolon), and local infection producing trismus. If diagnosis is initially doubtful the answer will be revealed as the disease progresses, though this may be rapid, and life-endangering spasms may occur suddenly and unexpectedly. Observation should therefore be undertaken in the intensive care unit.

\section{INCUBATION PERIOD AND PERIOD OF ONSET}

The incubation period is the interval between wounding and the first symptom of tetanus. We could define this period in 65 of our patients (table I). In severe cases the incubation period tends to be short but a long interval is no guarantee of a mild attack. The period of onset is the interval between the first symptom and the first spasm, and this also correlates with the severity of the attack (table II), but again severe tetanus may follow a prolonged period of onset.

\section{wOUNDS}

In 65 patients a wound was considered to be the likely source of infection, although Clostridium tetani was cultured from only 17 of these. Most of the wounds were minor-for example, 12 were caused by small splinters of wood or thorns-and 30 patients did not consider their injury serious enough to warrant medical attention. Of those who did seek medical attention, 25 were given tetanus toxoid and 21 received prophylactic antibiotics, but none received antitetanus serum, either equine or human, when the wound was treated. Five cases were thought to be due to infection of varicose ulcers on the leg, probably contracted when manuring the garden or muck-spreading while wearing rubber boots. A further three cases were attributed to infection of chronic ulcers (pressure sores in two cases and a squamouscell carcinoma in the other). Two followed elective surgery, one an arthrodesis of the ankle joint, in which $\mathrm{Cl}$ tetani was subsequently grown from the operation site, and one after an ileal conduit operation.

No obvious source of infection was identified in the remaining 25 patients, although most were manual workers who sustained frequent

TABLE I-Incubation period according to severity of tetanus in 65 patients

\begin{tabular}{|c|c|c|c|c|c|c|c|c|c|c|c|c|c|c|c|}
\hline $\begin{array}{l}\text { Incubation } \\
\text { period (days): }\end{array}$ & 4 & 5 & 6 & 7 & 8 & 9 & 10 & 11 & 12 & 13 & 14 & 15 & 16 & 17 & 20 \\
\hline \multirow{2}{*}{$\begin{array}{l}\text { Very severe } \\
\text { Severe } \\
\text { Mild or } \\
\text { moderate }\end{array}$} & $\begin{array}{l}2 \\
3\end{array}$ & $\begin{array}{l}1 \\
5\end{array}$ & $\begin{array}{l}4 \\
9\end{array}$ & $\begin{array}{l}2 \\
4\end{array}$ & $\begin{array}{l}4 \\
3\end{array}$ & $\begin{array}{l}2 \\
4\end{array}$ & 5 & $\begin{array}{l}1 \\
2\end{array}$ & 1 & $\begin{array}{l}1 \\
1\end{array}$ & $\begin{array}{l}1 \\
1\end{array}$ & & 1 & 1 & 1 \\
\hline & & & & & & & & & 1 & 2 & 1 & 2 & & & \\
\hline
\end{tabular}

TABLE II-Period of onset of disease in 78 patients, according to severity of tetanus

\begin{tabular}{|c|c|c|c|c|c|c|c|c|c|c|}
\hline $\begin{array}{l}\text { Period of } \\
\text { onset (days): }\end{array}$ & $<1$ & $1-2$ & $2-3$ & $3-4$ & 4-5 & $5-6$ & $6-7$ & $7-8$ & 10 & 12 \\
\hline \multirow{2}{*}{$\begin{array}{l}\text { Very severe } \\
\text { Severe } \\
\text { Moderate or } \\
\text { mild }\end{array}$} & $\begin{array}{l}6 \\
5\end{array}$ & 21 & 16 & $\begin{array}{l}1 \\
5\end{array}$ & 4 & 1 & 4 & 1 & 1 & $\begin{array}{l}1 \\
1\end{array}$ \\
\hline & & & 1 & 1 & & 1 & & & 1 & \\
\hline
\end{tabular}

minor scratches and abrasions. The nature of these wounds and the circumstances of wounding have been reviewed in more detail by Atrachki and Wilson. ${ }^{2}$

\section{IMMUNITY}

We obtained a reliable history in 82 of our patients; 78 had never received tetanus toxoid and two had received one dose only. Two had received the full course of three injections, in one case eight years and in the other three years before injury; neither received a booster dose of toxoid at the time of injury and the second developed only a mild attack of tetanus.

\section{TREATMENT}

All patients received the following specific treatment. The wound, when identified, was excised widely, all contaminated tissue being removed and sent for microscopical examination and culture. This was often time-consuming when several wounds were suspect, and occasionally amputation of an affected digit was required. The resulting defect was not usually closed primarily, and was packed with gauze soaked with hydrogen peroxide or paraffin gauze impregnated with an antibacterial agent for up to five days, when delayed closure was undertaken using either direct suture or splitskin grafts.

Benzylpenicillin $1 \mathrm{MU}$ six-hourly was given intramuscularly for one week, but no further antibiotics were administered unless intercurrent infection developed. Early in the series patients were given $10000-150000 \mathrm{U}$ of horse antitetanus serum or human serum prepared locally. The last 14 cases received Humotet (human antitetanus immunoglobulin) 2000-4000 U intramuscularly. Symptomatic treatment was according to the severity of the case, graded according to the method of Ablett. ${ }^{3}$ Mild (grade 1) cases with no dysphagia or respiratory difficulty were managed with sedatives, diazepam and the opiates being the current drugs of choice. Moderate (grade 2) cases with more pronounced spasticity and some interference with swallowing and respiration required tracheostomy in addition to sedatives. Severe (grade 3a) cases with gross spasticity and major spasms required paralysis with curare and artificial ventilation. Very severe (grade 3b) cases with evidence of sympathetic overactivity (as described by Kerr et $a l^{4}$ ) required in addition very heavy sedation, anaesthesia, or adrenergic blockade. ${ }^{5}$

As the disease may progress very rapidly, all patients were admitted to the intensive-care unit for initial observation. Sudden severe spasms needed rapid paralysis and intubation on several occasions and transport arrangements must also cater for this eventuality. Other measures were directed at preventing and controlling the many complications that arose.

\section{Results}

The condition in 90 of the patients was judged severe enough to require paralysis, 21 of these being very severe cases. Only seven had a mild attack not requiring tracheostomy and in three symptoms were moderately severe needing tracheostomy but not paralysis. Ten deaths were attributable to the disease or its treatment, eight during treatment, one in the immediate convalescent period, and one some years later. The remaining patients recovered, most to complete health, and results of follow-up of these patients are the subject of another paper.

The average duration of paralysis was 21 days (range 5-44 days). The duration of the illness was more uniform than the data in table III suggest. Those paralysed for short periods tended to have milder disease and required paralysis only at the peak of their illness, while those paralysed for longer had developed intercurrent problems that delayed their "weaning" from artificial ventilation. Although the severity of tetanus is variable, its duration seems fairly constant, the symptoms of even mild cases lasting three to four weeks. The average stay in the unit was 31 days. 


\section{CAUSE OF DEATH}

Table IV shows the cause of death in the eight patients who died in the unit. One woman died during convalescence from pulmonary embolism and a boy of 14 sustained severe brain damage during treatment and died three years later. The cause of the brain damage was never fully elucidated; no hypoxic incidents were recorded and the cause was possibly a cerebral venous thrombosis producing venous infarction. The two cases of sudden cardiac arrest were thought to be largely hypoxic in origin, occurring during tracheal suction in paralysed patients with "sticky" chests, and before we introduced preoxygenation before suction. Both developed severe bradycardia progressing to cardiac arrest, and one of these patients and another who was successfully resuscitated from a similar incident were the only patients in the series who received beta-blockers.

TABLE IV-Cause of death in eight patients with tetanus

\begin{tabular}{|c|c|c|c|}
\hline Sex & Age & Severity of tetanus & Cause of death \\
\hline $\begin{array}{l}M \\
M \\
F \\
M\end{array}$ & $\begin{array}{l}87 \\
24 \\
66 \\
71\end{array}$ & $\begin{array}{l}\text { Severe } \\
\text { Very severe } \\
\text { Very severe } \\
\text { Very severe }\end{array}$ & $\begin{array}{l}\text { Tension pneumothorax } \\
\text { Sudden cardiac arrest } \\
\text { Sudden cardiac arrest } \\
\text { Haemorrhage from acute } \\
\text { gastric erosions }\end{array}$ \\
\hline $\begin{array}{l}M \\
M \\
F \\
F\end{array}$ & $\begin{array}{r}57 \\
57 \\
68 \\
5\end{array}$ & $\begin{array}{l}\text { Severe } \\
\text { Severe } \\
\text { Severe } \\
\text { Very severe }\end{array}$ & $\begin{array}{l}\text { Bronchopneumonia } \\
\text { Bronchopneumonia } \\
\text { Staphylococcal pneumonia } \\
\text { Anaphylactic reaction } \\
\text { attributed to horse } \\
\text { antitetanus serum }\end{array}$ \\
\hline
\end{tabular}

\section{RESPIRATORY COMPLICATIONS}

Respiratory complications were common and accounted for six of the eight deaths on the unit; to keep the chest of a paralysed patient clear for some three weeks is a continual struggle against retained secretions, atelectasis, and pneumonia. Tension pneumothorax developed in five patients, one of whom died, and obstruction of the tracheostomy by secretions resulted in hypoxia in two patients, both of whom were successfully resuscitated. Severe bleeding from the trachea due to trauma from the tracheostomy cuff and suction catheters occurred in three patients. All were receiving prophylactic anticoagulants and the bleeding was controlled by reversal of anticoagulation. Respirator failure and disconnection occurred occasionally, but was always detected quickly enough to prevent any serious hypoxia. Introduction of more advanced alarm systems recently has reduced the likelihood of disaster due to these accidents, but the most important safeguard is still the presence of an experienced and vigilant nurse at the bedside at all times.

\section{CARDIOVASCULAR COMPLICATIONS}

Cardiovascular complications were less troublesome, except in the 21 patients with very severe disease, who had tachycardia, labile hypertension, peripheral vasoconstriction, and myocardial irritability attributable to sympathetic overactivity. ${ }^{4}$ Episodes of unexplained hypotension as described by Corbett et $a l^{6}$ also occurred in some of these patients, but usually responded promptly to the simple measures ${ }^{6}$ of head-down tilt, minor painful stimuli, and raising the arterial carbon dioxide concentration. Severe peripheral oedema developed in several patients despite careful monitoring of fluid balance and apparently normal renal and cardiac function. This responded to frusemide, but was more severe than would have been expected from the effects of hypoproteinaemia, intermittent positive-pressure respiration, and immobility alone.

Clinically obvious deep venous thrombosis of the legs occurred in nine patients and pulmonary embolism in three, one of which was fatal. Early in the series patients who were thought to be at particular risk were anticoagulated with warfarin; the last ten patients were given 5000 units of heparin subcutaneously twice daily and had no thrombotic incidents.

\section{GASTROINTESTINAL AND METABOLIG COMPLICATIONS}

Some gastrointestinal stasis occurred in most patients during the first seven to ten days, with a silent, but not distended, abdomen, which made feeding by nasogastric tube difficult or impossible. Acute gastric dilatation occurred in four and frank paralytic ileus in two. Haemorrhage from acute gastric erosions, severe enough to require partial gastrectomy, occurred in two patients, one of whom died. Constipation was common, aperients and enemata normally being required; this problem should not be taken lightly, since faecal impaction resulted in intestinal obstruction in one case and stercoral perforation of the caecum in another. Abdominal complications are difficult to diagnose early because the patient cannot easily convey his complaint of pain and muscle relaxants mask guarding and rigidity.

Jaundice of hepatocellular type developed in five patients, but settled uneventfully and could be explained by episodes of hypoxia or hypotension. All patients lost weight during their illness, largely because of the initial gastrointestinal stasis; since most patients were well nourished before their illness, we did not resort to intravenous hyperalimentation unless stasis persisted for over seven to ten days. Progressive anaemia always develops and usually requires transfusion at least once. Many factors probably contribute to this in a long, severe illness, particularly when many blood samples must be taken.

\section{URINARY COMPLICATIONS}

All patients except those with mild grade 1 disease had an indwelling urinary catheter with closed drainage throughout their illness. Specimens were sent for bacteriological examination twice weekly; clinical and laboratory evidence of infection was common and such infections responded readily to appropriate antibiotic treatment and eventual removal of the catheter. One elderly man required a transurethral prostatectomy at the end of his illness.

\section{PROLONGED RECOVERY AND RESIDUAL NEUROLOGICAL SIGNS}

The disease usually regresses sufficiently to permit paralysis to be withdrawn after two to three weeks, but muscular rigidity, especially trismus and neck stiffness, may persist for some weeks. Spasm of the calf muscles also seems to be persistent and may result in permanent contracture unless intensive physiotherapy is begun; one patient early in the series required lengthening of the tendo achilles. Residual cranial nerve palsies during recovery occurred in all patients who presented with cephalic tetanus, and weakness of the extraocular muscles was common. All recovered in two to three weeks except one patient, who had such severe bulbar palsy that motor neurone disease was suspected. Nevertheless, he made a slow but complete recovery over six months.

Disorientation, emotional lability, and depression during recovery is common. In two patients this phase lasted for weeks rather than days; both eventually returned to normal and had a long, severe illness. They were sedated by particularly heavy doses of diazepam.

\section{Discussion}

Many patients in this series required full paralysis plus intermittent positive-pressure respiration. This may be because only the more severe cases were referred from other hospitals, but probably also reflects an increasing confidence that early resort to tracheostomy and paralysis is less hazardous and more comfortable for the patient than persisting with a conservative sedative regimen. If this policy is adopted full intensive-care facilities must be available, with a fully trained nurse to care for each patient at all times. Allowing for time off, holidays, and sick leave we find that a complement of $5 \cdot 8$ nurses is necessary for each patient.

The mortality rate of $10 \%$ compares favourably with most series, although Sanders ${ }^{7}$ reports a remarkably low mortality rate of $7 \%$ in a centre without intensive-care facilities after use of intrathecal antitetanus serum. The benefit of this route of administration is not, however, confirmed by results of the series of Vakil et al, ${ }^{8}$ in which $250 \mathrm{U}$ of human tetanus immunoglobulin was injected into the cisterna magna. The manufacturers state that Humotet as at present formulated is recommended for intramuscular use only and we use it by this route at the lower end of the recommended dosage scale (30- 
$300 \mathrm{IU} / \mathrm{kg}$ ) because of the volumes (Humotet contains $250 \mathrm{U} / \mathrm{ml}$ ) and lack of evidence that higher doses are any more effective.

The deaths in this series were due to complications that may arise in any severely ill patient who is paralysed and artificially ventilated for this length of time, and were not directly attributable to tetanus. The single most troublesome problem was control of the cardiovascular effects of sympathetic overactivity in the patient with very severe disease. We relied largely on heavy sedation for control and only two patients received beta-blocking drugs at a modest dosage of $10 \mathrm{mg}$ propranolol six-hourly via nasogastric tube. Both of these young and previously fit patients developed sudden bradycardia and cardiac arrest during tracheal suction. This association with beta-blockers may be coincidental, but has led us to be cautious in using these drugs. Removing sympathetic myocardial drive may, in those dependent on such drive, lead to cardiac failure. If this occurs in patients with tetanus, who have been shown to have increases in cardiac output of $160-250 \%$, tracheal suction may produce the final cardiac insult of hypoxia and unopposed reflex vagal stimulation resulting in bradycardia and cardiac arrest. Hypoxia from tracheal suction may be eliminated or minimised by preoxygenation and careful suction technique, but our caution in using beta-blockers is reinforced by a report from Buchanan ${ }^{9}$ of the death of a 7 -year-old child with tetanus, which was associated with the use of propranolol.

We thank Mr D H Wilson for his help and encouragement in writing this paper; Dr J J L Ablett, who treated most of the patients early in the series; Mrs J L Sheard and Mrs S Barlow for secretarial help; Roche Ltd for financial help; and the nursing staff of the intensive care unit upon whose skill and devotion successful treatment of these patients largely depends.

\section{References}

${ }^{1}$ Faust, R A, Fournal of Trauma, 1976, 16, 755.

2 Atrachki, S A, and Wilson, D H, British Medical fournal, 1977, 1, 179.

3 Ablett, J J L, Symposium on Tetanus in Great Britain. Leeds, 1967.

4 Kerr, J H, et al, Lancet, 1968, 2, 236.

5 Prys-Roberts, C, Corbett, J L, and Kerr, J H, Lancet, 1969, 1, 542.

6 Corbett, J L, Spalding, J M, and Harris, P J, British Medical fournal, $1973,3,423$.

7 Sanders, R K, et al, Lancet, 1977, 1, 974.

8 Vakil, B J, Armitage, P, and Laurence, D R, Proceedings of the Fourth International Conference on Tetanus, Dakar, Senegal, p 423. Lyon, Fondation Merieux, 1975.

${ }^{9}$ Buchanan, N, et al, British Medical fournal, 1978, 2, 254.

(Accepted 12 March 1979)
Is there any serious danger of lead poisoning in the kits that can now be bought for making toy soldiers in moulds? A typical mixture for heating seems to be $40^{\circ}$ tin and $60^{\circ}{ }_{\circ}$ lead.

The danger from melting lead or lead alloys arises from the formation of oxide on the surface of the lead or, if heated above $700^{\circ} \mathrm{C}$, from lead fumes. If only relatively small amounts of lead are melted and are not kept hot for long periods no significant amount of dross should be formed. For normal moulding of toy soldiers there should be no need to heat the alloy above about $350-400^{\circ} \mathrm{C}$, so that the amount of fume should be negligible. The only real risk to health is if young children with pica are given such toys to play with and they chew them regularly. If manufacture is carried out on a small commercial basis then strict cleanliness is required. Any oxide formed should be disposed of in tins with tightly fitting lids or sealed plastic bags in accordance with the law on disposal of toxic waste.

A 67-year-old man suffered from dry painful eyes after taking practolol for five years. Treatment was changed to propranolol three years ago but the discomfort persists. Should he stop the treatment and what, if any, treatment would cure his ocular condition?

Definite functional improvement may be expected in eyes that have shown adverse reactions to systemic treatment with practolol within a few months of withdrawing the drug unless they are severely damaged at the time of the initial drug reaction. But the reduction in tear flow may persist for longer. Furthermore, these eyes remain at risk from secondary infection and secondary changes in the lids. ${ }^{1}$ Treatment of the dry eyes is essentially frequent rehydration of the eyes with artificial tear drops (BJ6 or hypromellose). In addition, mucolytic drops (acetylcysteine, $5 \%$ or $10 \%$ ) to control the stringy, tenacious mucus and local antibiotics to control the secondary infection of the lid margin and conjunctivae may be necessary. Patients have developed red or sore eyes while on propranolol, ${ }^{2}$ but in this patient the ocular symptoms are unlikely to be directly related to the propranolol. In a recent study nearly one-quarter of the patients being treated with propranolol or other hypotensive drugs complained of gritty, red, or sore eyes whether or not they were taking propranolol. ${ }^{3}$ Since the ocular side effects of prolonged practolol administration are in the cornea and conjunctiva and are related to deficient tear secretion and the formation of an autoantibody that has an affinity for the intercellular zones of squamous epithelium ${ }^{4}$ evidence of changes in the cornea and conjunctiva should be sought if a "practolol syndrome" is suspected.

1 Wright, P, British Medical fournal, 1975, 1, 595.

Cubey, R B, and Taylor, S H, British Medical fournal, 1975, 4, 327

- Rollery, C T, et al, British fournal of Clinical Pharmacology, 1977, 4, 295.
Is it necessary to test for hepatitis- $B$ antigen in every case of hepatitis in general practice?

Of all cases of acute viral hepatitis in Britain, $30^{\circ}$ of cases in adults are caused by hepatitis $B$ infection. ${ }^{1}$ Some cases are acquired parenterally, and sexual transmission, especially among male homosexuals, is another well-recognised route. Many cases, however, occur sporadically with no apparent source of infection. Although hepatitis B tends to be more severe and prolonged, clinically it is often difficult to distinguish between $B$ and non-B hepatitis. In children hepatitis $B$ virus infection is rare, but in adults all cases of acute hepatitis should be tested for the hepatitis B surface antigen ( $\mathrm{HBsAg}$, "Australia antigen"). Apart from the importance of documentation, there are three important practical reasons for this. Firstly, special care must be taken with the handling of blood from positive cases. Secondly, because of the possibility of transmission to a conjugal partner, cases of hepatitis found to be positive should be advised to refrain from sexual intercourse until they become HBsAg negative. Finally, 5\% of positive cases remain positive and develop chronic liver disease, ${ }^{2}$ even though they may have apparently recovered from the acute episode. In this last group of patients liver biopsy is mandatory since long-term immunosuppression may be necessary to arrest progression of the disease. This is in contrast to hepatitis A ("infectious hepatitis"), for which there is no evidence for progression to chronic liver disease.

Finally, as many as one-half of all cases of acute hepatitis are due to neither the A nor B viruses. Some of these follow parenteral transmission, although most arise sporadically. ${ }^{3}$ In the acute phase such cases are indistinguishable from hepatitis A and B. Like type B cases, some will progress to chronic liver disease. ${ }^{4}$ The virus particle for these "non-A: non-B" cases has not yet been identified, but this and the development of serological tests for diagnosis ${ }^{4}$ will be the next major step forward.

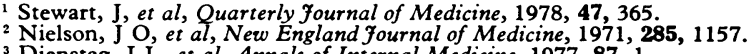

3 Dienstag, J L, et al, Annals of Internal Medicine, 1977, 87, 1.

- British Medical fournal, 1978, 1, 942 .

What is papillary carcinoma of the Fallopian tube and how should it be treated?

It is a relatively rare tumour, tending to be diagnosed late. The primary treatment is surgical. Depending on the extent of the disease seen at laparotomy and microscopically it may be decided to irradiate the pelvis. The place of chemotherapy is at present undetermined but may be tried. The prognosis is poor, with not more than $25 \%$ fiveyear survival. 